\title{
Ninth-grade students' perceptions on the design-thinking mindset in the context of reverse engineering
}

\author{
Luecha Ladachart $^{1}$ (D) . Jaroonpong Cholsin ${ }^{2}$. Sawanya Kwanpet ${ }^{2}$. \\ Ratree Teerapanpong ${ }^{2}$. Alisza Dessi ${ }^{2}$ - Laksanawan Phuangsuwan ${ }^{2}$. \\ Wilawan Phothong ${ }^{3}$ (D)
}

Accepted: 27 August 2021 / Published online: 2 September 2021

(c) The Author(s), under exclusive licence to Springer Nature B.V. 2021

\begin{abstract}
Recently, design thinking has become recognized as a necessity for every student, especially when they engage in design-based learning, as a pedagogical approach to science, technology, engineering, and mathematics education. However, design-based learning is mostly based on forward engineering, in which students' design thinking can be nurtured by designing unknown solutions. Little is known about whether design thinking can be facilitated in the context of reverse engineering, when students learn from already designed products. This study therefore seeks to explore the perceptions of 38 ninth-grade students on the characteristics of design thinking before and after a four-week reverse engineering project, using Likert scales to measure six aspects of design thinking, namely (a) being comfortable with uncertainty and risks, (b) human-centeredness, (c) mindfulness to the process and impacts on others, (d) collaboratively working with diversity, (e) orientation to learning by making and testing, and (f) being confident and optimistic to use creativity. The data were analyzed using descriptive and inferential statistics, including means, standard deviations, paired-samples t-tests, and Wilcoxon signed-rank tests. The results indicate that two aspects, human-centeredness and being confident and optimistic to use creativity, were significant ( $p=0.008$ and $p=0.043$, respectively), with size effects of 0.43 and 0.34 , respectively. Based on this potential, reverse engineering can be a design-based learning approach to facilitate students' design thinking. It is recommended that instructional activities involving reverse engineering maintain some degree of ambiguity and risk to prevent design fixation among students.
\end{abstract}

Keywords Design-based learning $\cdot$ Design thinking $\cdot$ Reverse engineering $\cdot$ STEM education

Luecha Ladachart

ladachart@gmail.com

1 Department of Curriculum and Instruction, School of Education, University of Phayao, Phayao, Thailand

2 Department of Science and Technology Learning, Phayaophithayakhom School, Phayao, Thailand

3 Department of Educational Technology, School of Education, University of Phayao, Phayao, Thailand 


\section{Introduction}

Science, technology, engineering, and mathematics (STEM) education has been internationally recognized as a reform movement in education ( $\mathrm{Li}$ et al., 2020), including in Asian countries (Wahono et al., 2020) such as Thailand (Promboon et al., 2018), where its key aims are to achieve STEM literacy among citizens and to increase the workforce in STEMrelated careers. In this regard, the engineering design process is pedagogically recommended as a key approach to integrated STEM education through which students learn to collaboratively solve real-life problems using relevant knowledge, skills, and dispositions (Kelly \& Knowles, 2016). Similar to engineers engaged in design-based tasks (Dym et al., 2005), students are required to employ design thinking, as it constantly operates when they engage in and learn through the engineering design process (Lammi \& Benker, 2013). Therefore, it is crucial that students are enabled to develop design thinking, in order for them to learn STEM meaningfully within the context of design-based activities. Indeed, Li et al. (2019) argue that design thinking "is important for every student to develop and have in the twenty-first century" (p. 94).

As a mode of thinking used in design-based activities (Li et al., 2019), design thinking can be defined as "an analytic and creative process that engages a person in opportunities to experiment, create and prototype models, gather feedback, and redesign" (Razzouk \& Shute, 2012, p. 330). It can also refer to an ability to combine empathy, creativity, and rationality to analyze and match solutions to particular problems (Wrigley \& Straker, 2015) when individuals (e.g., both engineers and students) aim to solve the problems of others, rather than their own problems. Such empathy makes design thinking different from other modes of thinking or problem solving, as solutions are specifically designed to solve the problems of users or clients (Dym et al., 2005). Moreover, as design-based activities involve an iterative process of creating, testing, and improving solutions, as well as collaborating with diverse people who share their knowledge, experience, and perspectives regarding the problem and solutions, design thinking entails a persistent and collaborative nature (Long, 2012). Given its empathic, creative, rational, collaborative, and ambiguous aspects, it is not surprising that design thinking can foster students' meaningful learning of STEM within the context of design-based activities (Cook \& Bush, 2018).

Despite the fact that a number of pedagogical models of design-based learning have been developed and examined their effects on students' learning of various domains of specific STEM disciplines, such as knowledge, skills, and attitudes (e.g., Apedoe et al., 2008; Chusinkunawut et al., 2020; Cotabish et al., 2013; Fortus et al., 2004; Kolodner et al., 2003; Korur et al., 2017; Mehalik et al., 2008), little attention has been paid to investigating whether, and what aspects of, such design-based learning can promote students' design thinking. Moreover, these models of design-based learning focus on forward engineering, in that students are challenged to solve engineering problems whose possible solutions, to some extent, are unknown to them. Only a few can be considered reverse engineering (McGowan et al., 2017), in which students engage in "taking a final product, dissecting [it] to understand its functionality, [and obtaining] design and other useful information" (Ali, 2005, p. 1).

Research has alluded to both advantages and disadvantages of using reverse engineering to develop students' design thinking. For example, when giving students who were new to design an opportunity to explore commercial products, Crismond (2001) noted that the students were likely to change from seeing products as givens to seeing products as designs, since they adopted the perspective of users toward such products. Thus, product 
evaluation can potentially cultivate the empathic approach of design thinking. Moreover, in their experimental study, Zhong et al. (2020) found that reverse engineering had positive effects on compatibility within students' groups and their creative self-efficacy, implying the development of the collaborative and creative nature of design thinking among students. However, McLellan and Nicholl (2011) observed that presenting a product for students to analyze its features and functions can inhibit creativity, because the students' ideas could be fixed on the given product, leading to design fixation (Schut et al., 2020). Thus, product analysis can potentially impede students to develop the creative nature of design thinking. Given these advantages and disadvantages, it is interesting to examine whether, and what aspects of, reverse engineering activities can facilitate students' design thinking.

\section{Reverse engineering}

Reverse engineering has been recognized as a pedagogical approach since Sheppard (1992) integrated what is called mechanical dissection into an engineering course at Stanford University. A key reason behind this integration is that learning can be more meaningful for undergraduate students when they are exposed to the technologies that surround them. By highlighting questions such as "how did others solve a particular (engineering) problem?", "how does the given solution work?", and "how was the given solution designed in that way?", undergraduate students can realize that all technologies are the result of an engineering design process, that all technological designs represent trade-offs, that there are certainly numerous solutions to a single design problem, and that the engineering design process typically starts with perceived needs, which become a set of functional specifications. Subsequently, the notion of reverse engineering was recommended and implemented for engineering design education at other universities (Ali, 2005). For example, Lamancusa et al. (1996) developed a course called product dissection at their universities, with some adaptation for undergraduate students to determine the difference between the success and failure of different designs in the marketplace.

As a pedagogical approach to engineering design education at undergraduate levels, Otto and Wood (1998) suggested that reverse engineering can be effectively used when it includes modeling, analysis, and redesign. At the beginning, students are presented with a product which is treated as "a black box" (p. 227). Then, they are encouraged to experience its operating parameters, to study it with respect to customer needs, and to hypothesize about its functionality, components, and working principles. Subsequently, they are allowed "the full disassembly of the product, design for manufacturing analysis, further functional analysis, and the generation of final design specifications" (p. 227). They are then asked to model the product through drawing and/or computer programs, before redesigning it for better performance. Younis and Tutunji (2012) organized reverse engineering activities into six steps, namely (1) pre-screening products, (2) observing the products' functionality and specifications, (3) dissecting the products' components and structures, (4) analyzing how those components function and work together, (5) building and testing a new product, and (6) modifying the newly built product. It has been found that reverse engineering provides an exciting way for undergraduate students to learn about design (Wood et al., 2001).

Recently, educators began to realize the potential of using reverse engineering to achieve specific learning objectives at K-12 or basic education levels where engineering practices are integrated into the curriculum to promote STEM education (Bureau of 
Academic Affairs \& Educational Standards, 2017; NGSS Lead States, 2013). Rouse and Rouse (2019), for example, used reverse engineering to introduce engineering concepts to third-grade students. In robotics education at fifth- and sixth-grade levels, Zhong et al. (2020) used four pedagogical models of reverse engineering, namely (1) deconstruction and recovery, where students deconstruct and restore a robot, (2) troubleshooting and recovery, where students analyze and solve the problems of a malfunctioning robot, (3) elements minitrim, where students deconstruct a robot and adjust some of its elements, and (4) structural innovation, where students deconstruct a robot and reconstruct its structure. In science education, McGowan et al. (2017) described a pedagogical model of reverse engineering which comprises five steps, namely (1) introducing a design challenge, (2) researching everyday solutions, (3) testing everyday solutions, (4) connecting everyday knowledge to scientific concepts, and (5) redesigning and sharing final solutions.

Given the various ways of using reverse engineering for educational purposes in different contexts, it is important to note that some of the steps may not be necessary or even appropriate for science education at basic education levels. For example, while it is necessary for undergraduate students studying engineering design to design a new product or to modify an original product for better performance (Otto \& Wood, 1998; Wood et al., 2001; Younis \& Tutunji, 2012), as this is key in their discipline, it seems less necessary or even impractical for students at K-12 or basic education levels to redesign a product or build a new product that functions better than the original. Rather, it seems more important for students in basic education to make a connection between the product's functionality and scientific concepts (Crismond, 2001; McGowan et al., 2017). Nonetheless, reverse engineering has potential as an alternative approach to design-based learning to facilitate students' learning in contexts that endorse STEM education, in addition to the forward-design-based learning approach. Regarding the current situation, it is important to explore the potential of reverse engineering in facilitating students' design thinking as a desirable characteristic of design-based learning.

\section{Design thinking}

Design thinking is a mode of thinking employed in design-based activities (Li et al., 2019) which can be described as "a systematic, intelligent process in which designers generate, evaluate, and specify concepts for devices, systems, or processes whose form and function achieve clients' objectives or users' needs while satisfying a specified set of constraints" (Dym et al., 2005, p. 104). Given the complexity of this process, design thinking thus entails various aspects, depending on the contexts where it is applied. There have been attempts to identify the elements or patterns of design thinking processes. For example, Sung and Kelly (2019) found that design thinking involves analyzing the situation, defining the problem, modeling ideas, designing prototypes, predicting results, questioning unexpected outcomes, and managing the process of designing. These aspects require design thinkers to have some desirable characteristics, which can be labeled using different terms, such as traits (Blizzard et al., 2015), attributes (Schweitzer et al., 2016), and mindsets (Dosi et al., 2018). In this paper, the term mindset is used, as it refers to "the set of opinions, beliefs and behaviors that characterize an individual" (Paparo et al., 2017, p. 369) when he or she engages in design-based activities.

Regardless of the terms used, it appears that design thinking is a multi-faceted concept. According to Dosi et al., (2018), design thinking can have as many as 19 aspects: 
(1) tolerance of ambiguity, (2) embracing risks, (3) human-centeredness, (4) empathy, (5) mindfulness of process, (6) holistic view, (7) problem framing, (8) team working, (9), multi-disciplinary collaboration, (10) being open to different perspectives, (11) orientation to learning, (12) experimentation, (13) bias toward action, (14) critical questioning, (15) abductive thinking, (16) envisioning new things, (17) creative confidence, (18) desire to make a difference, and (19) optimism to have an impact. However, as these aspects are not absolutely distinct, many of them can be merged. Schweitzer et al. (2016), for example, describe 11 aspects, namely that design thinkers are: (1) empathic toward people's needs and contexts, (2) collaboratively geared and embracing diversity, (3) inquisitive and open to new perspectives and learning, (4) mindful of process and thinking modes, (5) experientially intelligent, (6) taking action deliberately and overtly, (7) consciously creative, (8) accepting of uncertainty and open to risk, (9) modeling behaviors, (10) having a desire and determination to make a difference, and (11) critically questioning.

Given a vast list of design thinking aspects, however, it is neither reasonable nor practical to expect students, as novice designers, to develop all of these characteristics simultaneously. By applying exploratory factor analyses and regression models, Blizzard et al. (2015) identified an ample number of design-thinking characteristics for students: (1) collaboration, (2) experimentation, (3) optimism, (4) feedback-seeking, and (5) integrative thinking. Moreover, Cook and Bush (2018) highlighted five aspects of design thinking at elementary levels: (1) human-centeredness, (2) a bias toward action, (3) radical collaboration, (4) a culture of prototyping, and (5) mindfulness of process. Based on these lists, it can be summarized that design thinking generally entails empathy with people's problems, a desire to take action, and learning during the process of problem solving in order to have an impact on people's lives and societies. While designing, design thinkers wish to communicate ideas and collaborate with others, are open to diverse perspectives, are mindful to the process of problem solving, are aware of their own thinking modes, are comfortable with ambiguity and uncertainty, are confident in their creativity, embrace risks when trying different approaches or testing new ideas, and are resilient not to back down from challenging problems.

\section{Research question}

Despite the potential of reverse engineering in facilitating students' learning of various domains such as knowledge, skills, and attitudes used in specific disciplines of STEM, to date no research has investigated the potential of reverse engineering in promoting students' design thinking. Thus, the following research question has been formulated to guide the current study:

- Do students exhibit more positive perceptions regarding their own design thinking after engaging in reverse engineering activities, and if so, which aspects of design thinking?

\section{Research methods}

In order to address the research question, a quasi-experimental research study with a pretest-posttest design was utilized in this study. According to Chiang et al. (2015), a quasiexperimental study with a pretest-posttest design in an educational context involves 
comparing at least one group of students who complete the same test before and after an educational intervention in order to examine whether such an intervention, as the independent variable, influences their learning, as the dependent variable, which is measured twice using the same test. This research design is used because it is not practical to compare two equivalent groups of students, one which received the intervention and one which did not receive the intervention, in many educational settings where students are already assigned to classes. While the authors are aware of the limitations of the research design which could threaten the validity of the research results, such as history, maturation, and re-testing (Yu, 2021), useful insights regarding the influence of the educational intervention on students' learning can be gained in a valid manner. In this study, which was conducted regarding the instructional content of thermal expansion, the independent variable is the use of reverse engineering in design-based learning and the dependent variable is students' perception of their design-thinking mindset. The details of the research design are presented in the following section.

\section{Context}

This study took place in the largest secondary school in a province in the northern region of Thailand, where STEM education is endorsed as an educational movement. In this regard, the national science curriculum standards have been revised to include technology and design education (Bureau of Academic Affairs \& Educational Standards, 2017). In addition to requiring students to learn to use technology for everyday life and their future careers, the revised version of the national science curriculum standards requires students to learn to create and develop technology through engineering design practices. The Institute for the Promotion of Teaching Science and Technology (2015), Thailand's national organization driving STEM education, describes the engineering design process as a key pedagogical model comprising six steps: (1) problem identification; (2) related information search; (3) solution design; (4) planning and development; (5) testing, evaluation, and design improvement; and (6) presentation. This model, which can be considered a forwardengineering design-based approach, has been introduced to science teachers throughout the country. However, as Promboon et al. (2018) caution that no model of STEM education should be viewed as one-size-fits-all, developing alternative models of STEM education is necessary.

In the 2020 academic year, when this study began, the school had a total of 3406 students (1422 males and 1984 females) in grades 7-12. Located in the central area of the city, the school serves students from all districts of the province. There are 207 teachers at the school, in addition to the school administrators and office personnel. Of these teachers, 41 are science teachers: they include eight teachers in general science, 11 physics teachers, nine chemistry teachers, 10 biology teachers, and three foreign teachers. Five teachers (one in physics, one in biology, and three in chemistry) participated in the study as a team; together they are responsible for a STEM elective course at the ninth-grade level. Except for the biology teacher who is 58 years old and who typically works as the senior and supporting teacher of the team, the other four teachers are approximately 28-31 years old, all have approximately five years of teaching experience, and all have a master's degree in science education under the project titled the Promotion of Science and Mathematics Talented Teachers (PSMT), with scholarships supported by the Institute for the Promotion of Teaching Science and Technology (see Faikhamta et al., 2018, for details about this project). 
As the STEM elective course mainly aims to introduce students to the engineering design process, this team of teachers was interested in using reverse engineering as a new pedagogical approach, in addition to the model of design-based learning recommended by the Institute for the Promotion of Teaching Science and Technology (2015), to develop students' scientific understanding as well as design thinking. Consequently, they participated in this study with some incentive. Based on early meetings with two educators at the university located in the same province, a collective decision was made to develop a lesson about thermal expansion for students who selected STEM as their elective course. The reason for this decision was that thermal expansion is a scientific concept underlying the working principle of thermostats as a component of electrical equipment used in the students' everyday life (Subramaniam, 1999); thus, this topic could be meaningful for them to learn (McGowan et al., 2017). It is important to note, based on the tentative results of this research, that, after the reverse engineering activities (described below), the students demonstrated a significant improvement in their understanding of thermal expansion. However, it is not clear whether they would demonstrate a similar result regarding the perception of their own design-thinking mindsets.

\section{Activities}

As guided by the concept of design-based research (The Design-Based Research Collective, 2003), the two educators from the university designed an instructional unit on thermal expansion, as requested by the teachers, to implement with the students in the STEM elective course. In so doing, an integration between Younis and Tutunji's (2012) and McGowan et al.'s (2017) models were utilized to connect the process of reverse engineering to a scientific concept. Instead of following all six steps of Younis and Tutunji's (2012) model, only the first four steps were used, namely (1) pre-screening a product, (2) observing the product's functionality and specifications, (3) dissecting the product's components and structures, and (4) analyzing how those components function and work together. Then, one key step of connecting to a scientific concept, namely the fourth step of McGowan et al.'s (2017) model, was added, before the last step was to challenge the students to design and build their own product. In the last step, the students were not expected to design and build a product that functions better than the original one. Rather, the last step mainly aimed to provide the students with an opportunity to apply the scientific concept they had learned in the previous steps to properly solving a design challenge.

As illustrated in Fig. 1, the students were first allowed to explore the appearance of a bimetallic thermostat, on which they could see a temperature value. Then, they explored the functionality of the thermostat within an electric circuit containing a battery, a bulb, and wires, when it was immersed in a beaker of tap water being heated. After a discussion about the behavior of the thermostat, which functioned as an automatic switch, a dissected thermostat was given to the students to explore in detail, so that they were able to see two metallic strips making contact inside the thermostat. Moreover, they were allowed to fire the dissected thermostat to observe the trigger of the thermostat when heated. After discussing how the two metallic strips became disconnected, leading to the idea that heat made them expand, the students compared the diameter of the brass sphere before and after being fired. They also engaged in a role-playing activity, as they acted as metal particles vibrating and moving apart from each other when becoming heated, before viewing and discussing a video clip illustrating what happens to metal particles when they are heated. Finally, with three pieces of metal (i.e., one each of copper, aluminum, and brass), a roll of 


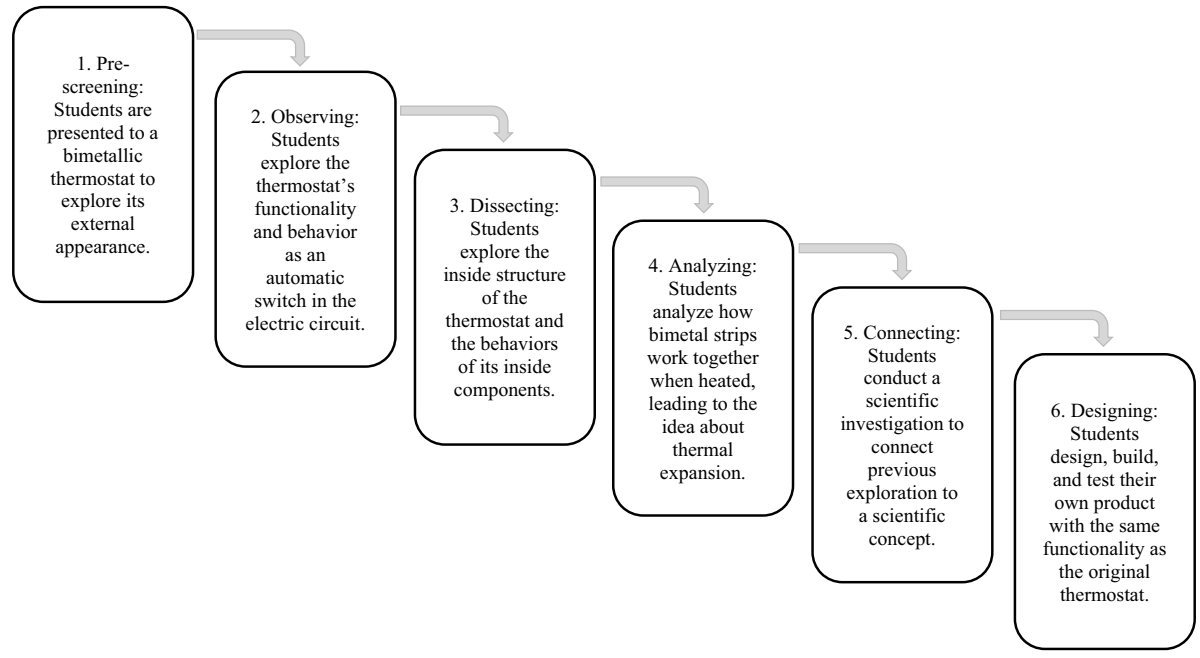

Fig. 1 Model of reverse engineering for design-based learning

adhesive tape, and a pair of scissors, they were challenged to design, build, and test their own thermostat to see whether it can act as an automatic switch in an electric circuit at least three times.

\section{Instrument}

In an attempt to measure a number of students' perceptions of their design thinking in a practical yet reliable way, a Likert-scale-type questionnaire was deemed appropriate (Blizzard et al., 2015; Dosi et al., 2018; Schweitzer et al., 2016). However, such a questionnaire had to be comprehensive and contextually sensitive enough when written and used in the context of this study. Thus, based on the literature review, the most extensive list of designthinking characteristics (Dosi et al., 2018) was used as the starting point. After translating about 70 items representing 19 characteristics of design thinkers, exploratory and confirmatory factor analyses were successively conducted with 297 and 593 secondary students, respectively. This resulted in 30 items representing six aspects of design thinking, namely (1) collaboratively working with diversity (five items), (2) being confident and optimistic to use creativity (eight items), (3) orientation to learning by making and testing (four items), (4) mindfulness to process and impacts on others (three items), (5) being comfortable with uncertainty and risks (six items), and (6) human-centeredness (four items); the loading factors were $0.852,0.822,0.879,0.974,0.784$, and 0.979, respectively. Details of the instrument can be found in the Appendix.

Given that "empathy [is the] most important piece of the design-thinking process" (Cook \& Bush, 2018, p. 99), it is important to note that the items originally belonging to the factor empathy in Dosi et al. (2018) list of design-thinking characteristics did not appear to constitute a single factor in the exploratory and confirmatory analyses conducted for developing the instrument for this study. Rather, some of the items were merged together with other factors (i.e., human-centeredness and mindfulness to process). In a sense, this is understandable, given that human-centeredness can refer to "developing empathy for the people for whom you are designing" (Cook \& Bush, 2018, p. 95). In another sense, 
this might mean that empathy does not operate only in the first stage of the design-thinking process, as graphically illustrated by the Institute of Design at Stanford (2019), but in the whole process of design-based activities. This hypothesis supports what Hess and Fila (2016) noted, namely that "empathy [...] functions from the beginning to the end of a design project" (p. 108). Thus, the emphatic aspect of design thinking was measured by several items belonging to human-centeredness and mindfulness to the process and impacts on others in this study.

\section{Data collection}

The reverse engineering activities were implemented in two elective STEM classes of ninth-grade students, which were conducted weekly for two 50-min periods, on Monday mornings and Tuesday evenings. The activities lasted for four weeks, or eight periods in total. The first class had 21 students (eight males and 13 females) and the second class had 24 students (16 males and eight females). In each class, the students worked in groups of three to which they were randomly assigned by the teachers. Given that the activities were conducted in the elective course, the students were from different normal classrooms and might not have known all of their present classmates. The reason for randomly assigning students to groups was that the teachers wanted them to get to know each other better and learn to work with classmates who were not their intimate friends. It is this aspect that reflects a characteristic of those who have a design-thinking mindset (Dosi et al., 2018). During these activities, the only male teacher with major in chemistry took the leading role, while the three female teachers played a supporting role by facilitating the students working in groups. The senior teacher and the two educators observed the classes as nonparticipants. All activities were recorded using a video camera placed at the back of the classrooms. Moreover, the teachers selected three groups in each class with voluntariness from the students and recorded verbal interactions within each group.

One week before and one week after the implementation of the reverse engineering activities, the students were individually asked to complete the five-point, Likert-scale questionnaire, comprising 30 items reflecting six characteristics of design thinking, shortly after they completed a conceptual test on thermal expansion. However, as this study was conducted during the COVID-19 pandemic, some students had to self-quarantine at home for 14 days to protect against the pandemic because they or their family members had visited other places during the New Year's holidays. As a consequence, only 17 students from the first class and 21 students from the second class completed all items in both the pre- and post-measurements. The data collected from these 38 students (18 males and 20 females) were pooled together, since there were no obvious differences in terms of instructional practices regarding design-thinking aspects introduced by the teachers in each class. With a four-week interval between the two measurements, it was less likely that re-testing came into play as a threat to the validity of the study, while history and maturation were inevitable (Yu, 2021). The pre-analysis of the reliability of the questionnaire confirmed that the instrument was reliable, since Cronbach's alpha was 0.92 and 0.90 for the pre- and post-measurements, respectively.

Before collecting data about students in the school, the educators sent the research proposal to their university's research ethics committees to examine whether it was in accordance with ethical principles in research involving human subjects. After receiving approval from the committees, the educators sent an official letter to the school principal to request permission to personally meet the teachers to present the research project in detail. During 
the meetings, the educators were cautious to avoid directly interacting with students; thus, interviews with students were not feasible. Moreover, by collectively considering the instructional activities, the educators and the teachers agreed that it might be too dangerous for the students to dissect a bimetal thermostat by themselves, given its small size and metal cover. Thus, it was safer for the students to observe an already dissected one. As the instructional activities involve the use of fire to heat objects to observe thermal expansion, potential danger from the fire was also considered. However, as the students were familiar with using alcohol lamps and the teachers were available to monitor the students, this danger was considered manageable. Before the data collection, the students were informed about the research project and then signed consent forms.

\section{Data analysis}

Given that the research question aimed to examine whether, and which aspects of, reverse engineering activities influenced ninth-grade students' perceptions on the characteristics of design thinking, descriptive statistics were used to calculate the mean scores and standard deviations of each aspect of design thinking, in both the pre- and post-measurements, to observe the general tendency of the data. Subsequently, inferential statistics were used to examine whether there was a significant difference between the mean scores for the two measurements for each aspect of design thinking. Following the approach of Morgan et al. (2013), the normality of pre- and post-measurement data regarding each aspect of design thinking were checked using Shapiro-Wilk tests, given that study included fewer than 50 students. The results of the Shapiro-Wilk tests indicated only data regarding three aspects (i.e., being comfortable with uncertainty and risks, orientation to learning by making and testing, and being confident and optimistic to use creativity) were normally distributed $(p>0.05)$ on both measurements, while the other three aspects (i.e., human-centeredness, mindfulness to the process and impacts on others, and collaboratively working with diversity) were not normally distributed $(p<0.05)$. Thus, paired-samples $t$-tests were used only for the normally distributed data. For data that were not normally distributed, non-parametric Wilcoxon signed-rank tests were used. In cases where there was a significant improvement in students' perceptions, the $d$ value of the size effect was calculated by dividing the mean of the paired difference by the standard deviation (for the paired-samples $t$-tests), or the $r$ value of the size effect was calculated by dividing the $\mathrm{z}$-score by the square root of the number of students (for the Wilcoxon signed-rank tests) to identify to what extent the reverse-engineering activities had affected the students' perceptions. Moreover, to identify which items significantly contributed to improvements in students' perceptions, the nonparametric Wilcoxon signed-rank tests were conducted to compare the mean scores for each item (Field, 2013).

\section{Results}

Before engaging in the reverse engineering activities, it was evident from the students' responses to the pre-measurement, as illustrated by Fig. 2, that they were most positive about collaboratively working with diversity, as the mean score for this aspect was 3.92 $(\mathrm{SD}=0.66)$. This was followed by human-centeredness, orientation to learning by making and testing, and mindfulness to the process and impacts on others, with the mean scores ranging from 3.60 to 3.63 ( $\mathrm{SD}=0.63,0.72$, and 0.62 , respectively). They were less positive 
$\because$ Collaboratively working with diversity

- Human-centeredness $* * *$

- Mindfulness to the process and impacts on others

$\because$ Orientation to learning by making and testing

- Being confident and optimistic to use creativity**

$\longrightarrow$ Being comfortable with uncertainty and risks

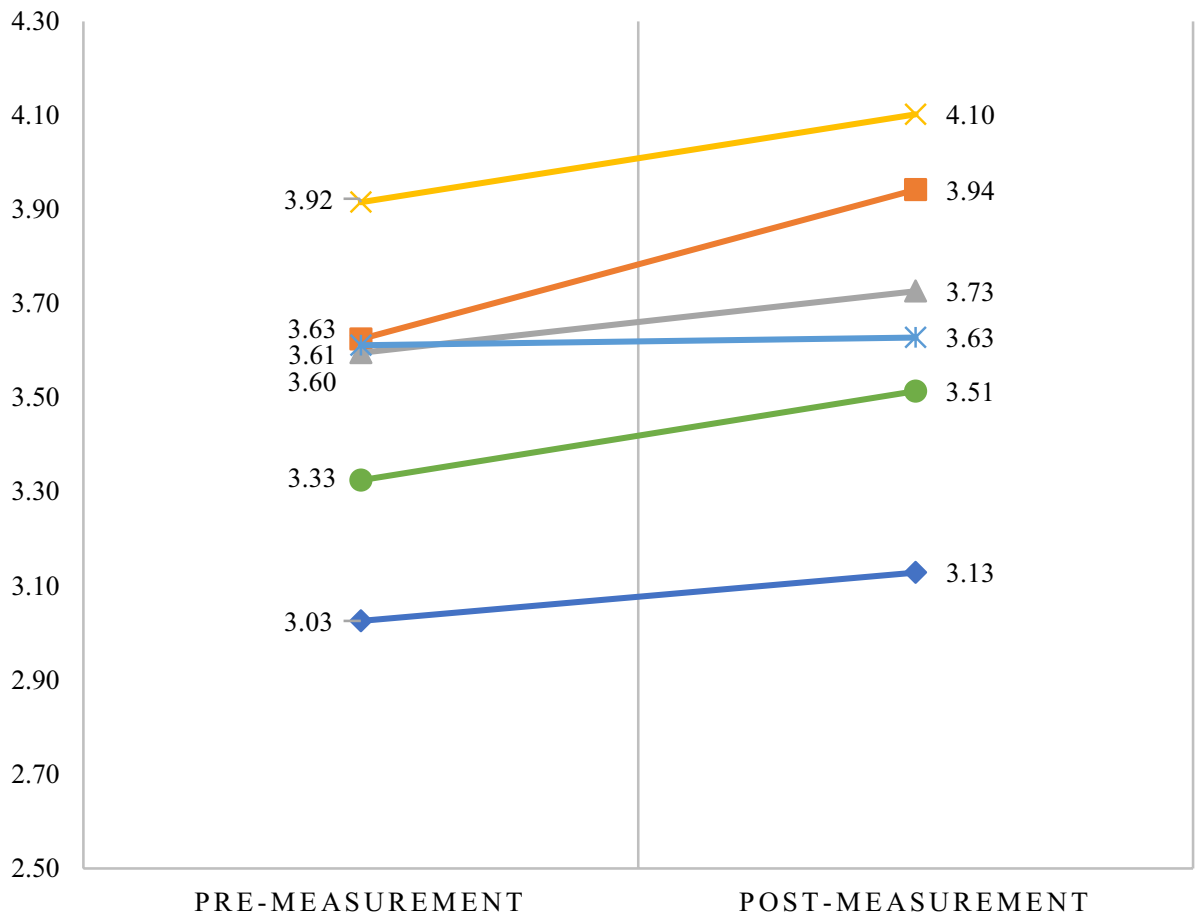

Fig. 2 Students' perceptions on each aspect of design thinking before and after reverse engineering activities. $* * * p<0.01 ; * * p<0.05$

about being confident and optimistic to use creativity, as the mean score for this aspect was 3.33 ( $\mathrm{SD}=0.68)$. The least positive perception was being comfortable with uncertainty and risks, with a mean score of $3.03(\mathrm{SD}=0.65)$. These results are understandable, given that "emotional and cognitive collaborative relationships have been established well in Thai science classrooms" (Chang et al., 2018, p. 11), where learning has been limited to "memorizing subject content" rather than encouraging students to use their creativity in solving open-ended and uncertain problems (Dahsah \& Coll, 2007, p. 228). Therefore, it is reasonable that the students were more likely to express their ease with collaborative and experiential learning, but less likely to express their confidence about the use of creativity and problem-solving skills.

However, after engaging in reverse engineering activities, the data from the post-measurement indicate that the students tended to be more positive about all aspects of their design thinking, with the exception of orientation to learning by making and testing which tended to be constant, as can be seen in Fig. 2. Moreover, when compared to other aspects, 
the tendency was similar to that in the pre-measurement. In other words, the students were still most positive about collaboratively working with diversity and human-centeredness, while they were less positive about being confident and optimistic to use creativity and being comfortable with uncertainty and risks. Despite these notable improvements in the students' perceptions, however, the paired-samples $t$-tests indicate that, of the three aspects whose data are normally distributed, only the aspect of being confident and optimistic to use creativity is significant, $t(37)=2.091, p=0.043$, with a small-to-medium size effect $(d=0.34)$. Additionally, the Wilcoxon signed-rank tests indicate that, of the other three aspects whose data are not normally distributed, only the aspect of human-centeredness is significant, $z=2.642, p=0.008$, with a medium-to-large size effect $(r=0.43)$. Therefore, it can be reasonably concluded that the reverse engineering activities facilitated the students' design thinking in some respects.

By conducting the non-parametric Wilcoxon signed-rank tests to compare the students' responses to each item in the pre- and post-measurements, it was possible to identify which items significantly contributed to the students' positive perceptions regarding each aspect of their design thinking. As summarized in Table 1, it was evident that there were nine items that contributed to the students' more positive perceptions on five aspects of design thinking at different significance levels. Regarding the aspect of human-centeredness, the students indicated that they were more aware of users' feelings, which can be a resource for designing solutions; thus, they wished users to participate in the process of designing. Regarding the aspect of being confident and optimistic to use creativity, the students indicated an increase in their creative self-efficacy, which made them more comfortable to communicate their novel ideas. Regarding the aspect of collaboratively working with diversity, the students were even more positive about sharing knowledge and working as a team with their classmates. Regarding the mindfulness aspect of design thinking, the students seemed to better realize the impacts of designed products. Moreover, they were more open to new contexts or situations with which they were not familiar.

Data from classroom observations and students' verbal interactions within groups can be used to triangulate and illustrate the results from the statistical analyses. After they were challenged to design a bimetal thermostat using three kinds of metal sheets, it is evident that the students, whose verbal interactions were recorded, thought that they would be able to make a bimetal thermostat in the same way the commercial product is made. For example, in one group of three male students (i.e., Eak, Jim, and Phum), Eak proposed the idea to "design like the original" thermostat. Jim agreed, saying, "The original looks tiny. (It) looks the best" design. This kind of thinking seemed to signal design fixation among the students (Schut et al., 2020). However, not all students tended to have design fixation, as Phum proposed an idea to make a three-layer thermostat having a shape like "an arch bridge," where "aluminum is middle" between brass and copper. As the students observed the commercial thermostat more closely and further discussed the properties of each kind of metal, they began to realize that it was much more difficult to design "like the original" than they initially thought, as can be seen in the following excerpt. Note that all names in all excerpts below are pseudonyms.

Eak: Teachers tell us to design. We must think. Shall we design its shape? Will we do it like the original?

Jim: If making like the original, it is difficult to do.

Eak: (Phum's idea to make a three-layer curve of metal strips is) also difficult, though.

Phum: Making like the original is more difficult.

Eak: Ouch! Very difficult. 


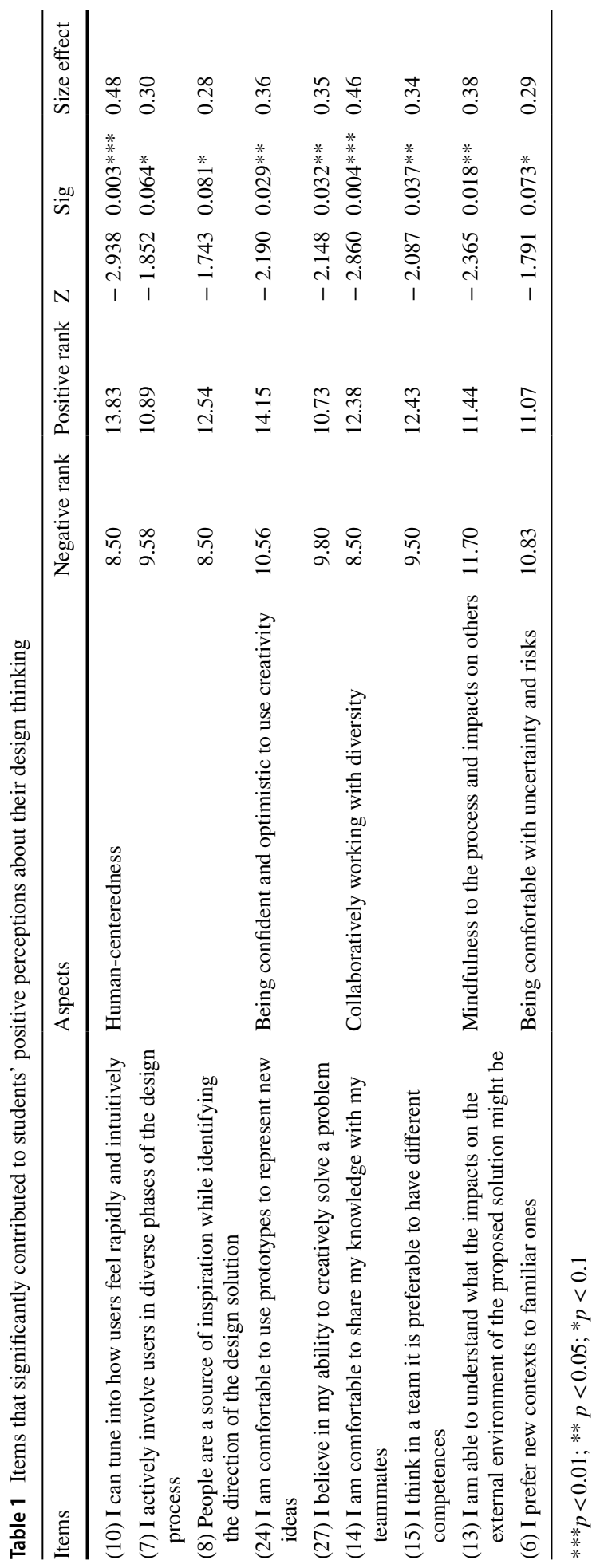


The excerpt above illustrates that, despite students' tendency toward design fixation, the design challenge is ambiguous in that the students could not simply duplicate or imitate the commercial thermostat. Given the availability of materials and equipment (i.e., three pieces of metal sheets, a roll of adhesive tape, and a pair of scissors), the design challenge requires the students to use their creativity, as evident in Eak's utterance to the group that "we must think." Moreover, the excerpt above confirms that, while encountering a difficulty in and having different ideas about designing a thermostat, the students were oriented to collaboration, as Eak and Phum encouraged all members of the group to express ideas in a neutral way. Specifically, they did not directly ask Jim, who was silent, to propose ideas. As a consequence of their collaboration, this group had various ideas for designing their own thermostat. Based on close observation of the commercial thermostat and Phum's initial idea of using a three-layer curve of metal strips, Eak proposed another idea: "to bend" one strip so that, when heated, it would become erect and contact an upper strip. The group subsequently agreed upon this idea to design their own thermostat in detail.

Phum: If here is hot-(He was interrupted before finishing the sentence).

Eak: (Interrupting) Here will bounce up. Initially, this one has a distance from the metal here, hasn't it? Electricity is cut here. Right? Something like that? ... If it gets hot, it will bounce up. Closed switch.

While the group was working on the idea described in the above excerpt, the leading teacher announced to the whole class that it was also necessary for the students' thermostat to be able to spontaneously turn off the electrical circuit when it became colder, saying, "Your thermostat should work automatically. ... You can see from the experiment (with the commercial thermostat) that it can turn on and turn off (the electrical circuit) so many times. It can be used repeatedly. Imagine that, if we make a thermostat based on what you design, I feel that it can be used only once. Think of how we can do to make it be used many times." Although not explicitly stated about users' needs, this announcement made students such as Eak think from the perspective of users in addition to that of designers, as he said to the group that "when it's cold, it must be as it was. But how will we do that? So difficult." It is evident that the supporting teachers, not only the leading teacher, emphasized users' perspectives when working with each group of students. For example, while observing one group of students, who designed a thermostat that was fixed onto a writing board, a supporting teacher challenged their design to encourage them to focus more on whether and how users could use their thermostat practically, as the following excerpt illustrates.

Pang: When it bounces up, it bounces up like this.

Teacher: How, then, when it gets heated?

Pang: What?

Teacher: When heating, how should you do? Will you lift (your thermostat) up? It's now fixed with the board.

Pang: Uh.

Teacher: Right? Now, you make it fix with the board. How can you do to make it moveable?

The excerpt above illustrates that, while designing a thermostat, some students, such as Pang, might concentrate on how to achieve the design challenge, leading them to ignore how their thermostat could be used practically. Crucially, the teachers helped them adopt 
not only the perspective of designers but also the perspective of users- that is the humancentered nature of design thinking.

\section{Discussion}

As STEM education has been an educational movement in many countries ( $\mathrm{Li}$ et al., 2020; Wahono et al., 2020), design-based learning has become an integrated approach to teaching and learning STEM (Kelly \& Knowles, 2016). The reasons for the use of design-based learning in $\mathrm{K}-12$ education are that design is the defining aspect of engineering (Pleasants \& Olson, 2019) and that engineering can meaningfully connect mathematics, science, and technology to help students learn the nature of STEM (Quinn et al., 2020). Research has demonstrated that engineering design-based activities can promote students' learning of STEM in many respects-not only disciplinary knowledge (Fortus et al., 2004), skills (Kolodner et al., 2003), and attitudes (Wendell \& Roger, 2013) but also application of knowledge (Wendell \& Lee, 2010), learning skills (Kolodner et al., 2003), and creativity (Korur et al., 2017). Despite the variety of learning outcomes shown to result from engineering design-based learning, little attention has been paid to design thinking (Cook \& Bush, 2018; Long, 2012). Even though recent research has suggested that students use design thinking while engaging in engineering design-based activities (Sung \& Kelly, 2019), whether and in what aspects students develop design thinking as a result of designbased learning is less clear.

Due to the necessity of design thinking for every student in the twenty-first century ( $\mathrm{Li}$ et al., 2019), ways to develop design thinking among students has been gaining increasing attention in education at K-12 education levels. It is recognized that for individuals (e.g., students and teachers alike) to develop design thinking, they need to engage in designbased activities (Bressler \& Annetta, 2021; Long, 2012). While most models of designbased learning in the literature are based on forward engineering, this study demonstrated that reverse engineering activities can also influence students to better perceive their own characteristics of design thinking, especially the aspect of human-centeredness. This result supports Crismond's (2001) observation that, when students explore commercial products in order to redesign them, the students tend to adopt users' perspectives and occasionally the marketing perspectives. The observation of these perspectives is also evident in studies by Ara et al. (2011) and Wangka and Ladachart (2021). Arguably, it is these perspectives that could enable students to begin seeing products as designs instead of products as givens (Crismond, 2001). It is these perspectives that provide a crucial foundation in the thinking of expert designers (Dym et al., 2005; Norman, 2013).

It has been questioned whether introducing students to a commercial product could inhibit their creativity when they are redesigning such a product with the same functionality (McLellan \& Nicholl, 2011). This study demonstrates that, after reverse engineering activities where students are exposed to the internal structure of a bimetal thermostat, the students were more positive about the use of their creative ideas to overcome the engineering design challenge to prototype their own bimetal thermostat. This result is consistent with Zhong et al.'s (2020) results, indicating that reverse engineering can even better facilitate students' creative self-efficacy (i.e., how they view their own abilities in creative product development) than forward engineering. In fact, as McLellan and Nicholl (2011) noted, tasks involving product analysis (i.e., a key part of reverse engineering) can be used if and only if they are designed to maintain ambiguity and risks in a balanced way. As can 
be seen in Fig. 2, students' perceptions about their comfort with uncertainty and risks are lowest among the aspects measured in both tests. This implies that the reverse engineering activities used in this study were ambiguous and challenging enough that they did not limit students' use of their creativity. This result is also confirmed by the students' verbal interactions within the groups.

Students also exhibited more positive perceptions about some items regarding the collaborative nature of design thinking after engaging in reverse engineering activities. This result should not be surprising, given that collaboration is normally preferable by students in many classrooms in Thailand (Chang et al., 2018). Even so, it seems that reverse-engineering activities can enhance students' perceptions about collaboration, as the process encourages them to share ideas, knowledge, and competencies to collaboratively solve an engineering problem. This result also supports Zhong et al. (2020), who found that the degree of compatibility within groups of students significantly improved after they had engaged in the process of reverse engineering, which requires them to cooperate and communicate at the beginning when they are trying to figure out how a product functions and works. In contrast to forward engineering activities, in which students can begin with "designing work directly and individually" (Zhong et al., 2020, p. 12), they can have "a conflict with peers in groups that occurred from a dispute about problems or errors and ideas they confronted," especially when "they are not successful in communicating their problem-solving process with others in order to fix the problems" (Chusinkunawut et al., 2020, p. 2).

However, reverse engineering is less influential in promoting more positive perceptions by students about their own design thinking in respect of their comfort with uncertainty and risks occurring when solving the given engineering problem, as well as their ability to be mindful to the engineering design process and impacts of its products. Regarding the comfort with uncertainty and risks, it is quite clear that students are not familiar with solving unknown problems, as this does not normally occur in many Thai classrooms (Dahsah $\&$ Coll, 2007). Thus, they are too concerned with failure in redesigning a product to function as reliably as a commercial product. As a consequence, they need more opportunities to experience the engineering design process to solve the problems of uncertainty and risks of failure. It is necessary to support them in this process, to see failure as an opportunity for learning (Long, 2012). Given that the engineering design process involves a number of activities, such as analyzing the situation, defining the problem, modeling ideas, designing prototypes, predicting results, questioning unexpected outcomes, and managing the process of designing (Sung \& Kelly, 2019), it is crucial that students are scaffolded to be mindful about the process of these activities, which requires metacognition on the part of the students (Kavousi et al., 2020).

\section{Implications}

In contexts where STEM education is promoted, in addition to forward engineering models of design-based learning, reverse engineering activities can be another approach to facilitate students' design thinking, as students in this study demonstrated more positive perceptions about their own characteristics associated with design thinking. In this regard, reverse engineering can be considered as a beginning step for students to learn some aspects of design thinking, such as human-centeredness, creativity, and collaboration. For some students who are new to design, beginning with forward engineering may not be so effective, 
given that they might not yet take users' perspectives and not know how to deal with conflicts with peers arising during the engineering design process. Once they are familiar with what it means to design via reverse engineering, they can engage in forward engineering more meaningfully and effectively. In proposing this approach, however, it is critical to note that the results of this study are gained from only a limited number of students completing a Likert-scale measurement. Future research is thus needed to verify its results. It may be more useful if future research focuses on comparing the design thinking of two equivalent groups of students who engage in either forward or reverse engineering, in order to identify the advantages and disadvantages of each approach.

\section{Appendix}

Items

(1) I feel comfortable with what is unknown

(2) I prefer new contexts to familiar ones

(3) I am comfortable dealing with problems that I cannot solve yet

(4) I enjoy when a solution does not result in what I expect

(5) I do not worry while solving problems that I do not know if it will be successful

(6) I like taking many chances, even if it leads me to make mistakes

(7) I actively involve users in diverse phases of the design process

(8) People are a source of inspiration while identifying the direction of the design solution

(9) During the design process, I try to understand what users need

(10) I can tune into how users feel rapidly and intuitively

(11) I easily empathize with the concerns of other people

(12) I am able to recognize when I am in a divergent or convergent phase of the process

(13) I am able to understand what the impacts on the external environment of the proposed solution might be

(14) I am comfortable to share my knowledge with my teammates

(15) I think in a team it is preferable to have different competences

(16) I am comfortable to work with people having diverse perspectives from mine

(17) I am comfortable to change my original opinions after listening to others

(18) I am open to collaborating with people having different backgrounds
Aspects of design thinking

Being comfortable with uncertainty and risks

Human-centeredness

Mindfulness to the process and impacts on others

Collaboratively working with diversity 


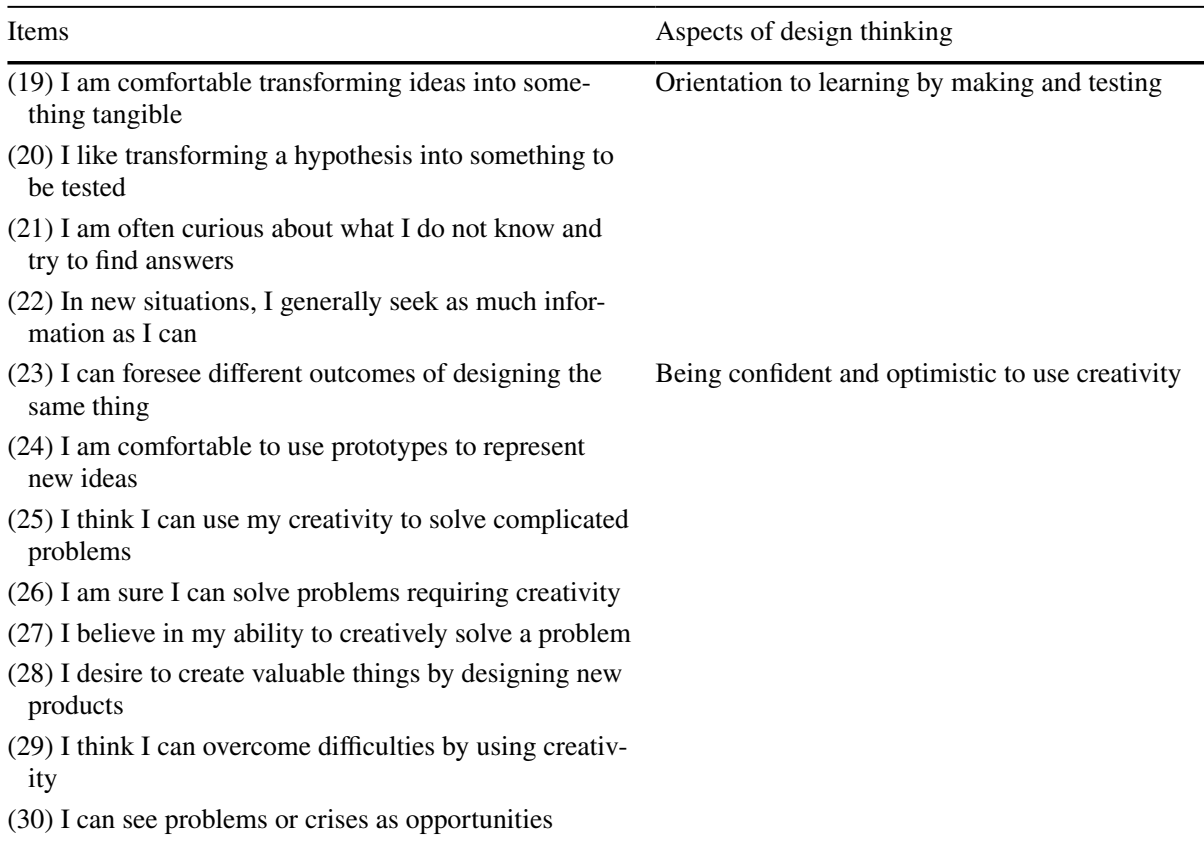

Acknowledgements This study was financially supported by Thailand Science Research and Innovation (previously known as the Thailand Research Fund) under the code RSA6180010. It was carried in accordance with the ethical principles approved by the University of Phayao's Human Ethics Committee under the number 2/048/62.

\section{References}

Ali, M. R. (2005). Why teach reverse engineering? ACM SIGSOFT Software Engineering Notes, 30(4), 1-4. https://doi.org/10.1145/1082983.1083004

Apedoe, X. S., Reynolds, B., Ellefson, M. R., \& Schunn, C. D. (2008). Bringing engineering design into high school science classrooms: The heating/cooling unit. Journal of Science Education and Technology, 17(5), 454-465. https://doi.org/10.1007/s10956-008-9114-6

Ara, F., Natarajan, C., \& Chunawala, S. (2011). Students as users and designers: Product evaluation and redesign by Indian middle school students. In Proceedings of the Fourth International Conference to Review Research on Science, Technology, and Mathematics Education. (pp. 95-100). Mumbai, India.

Blizzard, J., Klotz, L., Potvin, G., Hazari, Z., Cribbs, J., \& Godwin, A. (2015). Using survey questions to identify and learn more about those who exhibit design thinking traits. Design Studies, 38, 92-110. https://doi.org/10.1016/j.destud.2015.02.002

Bressler, D. M., \& Annetta, L. A. (2021). Using game design to increase teachers' familiarity with design thinking. International Journal of Technology and Design Education. https://doi.org/10.1007/ s10798-020-09628-4

Bureau of Academic Affairs and Educational Standards. (2017). Indicators and core learning content in science according to the basic education core curriculum B.E. 2551 (revised version B.E. 2560). Bangkok: Press of the Agricultural Co-operative Federation of Thailand.

Chang, J., Faikhamta, C., Na, J., \& Song, J. (2018). A comparison of science classroom environments between Korea and Thailand with a focus on their cultural features. Asia-Pacific Science Education. https://doi.org/10.1186/s41029-018-0028-1

Chiang, I.-C.A., Jhangiani, R. S., \& Price, P. C. (2015). Research methods in psychology (2nd Canadian). BCcampus. 
Chusinkunawut, K., Henderson, C., Nugultham, K., Wannagatesiri, T., \& Fakcharoenphol, W. (2020). Design-based science with communication scaffolding results in productive conversations and improved learning for secondary students. Research in Science Education. https://doi.org/10.1007/ s11165-020-09926-w

Cook, K. L., \& Bush, S. B. (2018). Design thinking in integrated STEAM learning: Surveying the landscape and exploring exemplars in elementary grades. School Science and Mathematics, 118(3-4), 93-103. https://doi.org/10.1111/ssm.12268

Cotabish, A., Dailey, D., Robinson, A., \& Hughes, G. (2013). The effects of a STEM intervention on elementary students' science knowledge and skills. School Science and Mathematics, 113(5), 215226. https://doi.org/10.1111/ssm.12023

Crismond, D. (2001). Learning and using science ideas when doing investigate-and-redesign tasks: A study of naïve, novice, and expert designers doing constrained and scaffolded design work. Journal of Research in Science Teaching, 38(7), 791-820. https://doi.org/10.1002/tea.1032

Dahsah, C., \& Coll, R. K. (2007). Thai grade 10 and 11 students' conceptual understanding and ability to solve stoichiometry problems. Research in Science and Technological Education, 25(2), 227241. https://doi.org/10.1080/02635140701250808

Dosi, C., Rosati, F., \& Vignoli, M. (2018). Measuring design mindset. In Proceedings of the 15th International Design Conference. (pp. 1991-2002). Dubrovnik: Croatia. https://doi.org/10.21278/idc. 2018.0493.

Dym, C. L., Agogino, A. M., Eris, O., Frey, D. D., \& Leifer, L. J. (2005). Engineering design thinking, teaching, and learning. Journal of Engineering Education, 94(1), 103-120. https://doi.org/10. 1002/j.2168-9830.2005.tb00832.x

Faikhamta, C., Ketsing, J., Tanak, A., \& Chamrat, S. (2018). Science teacher education in Thailand: A challenging journey. Asia-Pacific Science Education. https://doi.org/10.1186/s41029-018-0021-8

Field, A. (2013). Discovering statistics using IBM SPSS statistics (4th ed.). SAGE Publications.

Fortus, D., Dershimer, R. C., Krajcik, J., Marx, R. W., \& Mamlok-Naaman, R. (2004). Design-based science and student learning. Journal of Research in Science Teaching, 41(10), 1018-1110. https:// doi.org/10.1002/tea.20040

Hess, J. L., \& Fila, N. D. (2016). The manifestation of empathy with design: Finding from a servicelearning course. CoDesign, 12(1-2), 93-111. https://doi.org/10.1080/15710882.2015.1135243

Institute for the Promotion of Teaching Science and Technology. (2015). Basic knowledge about STEM education. Retrieved April 4, 2021, from http://www.stemedthailand.org/wp-content/uploads/2015/ 03/newIntro-to-STEM.pdf.

Institute of Design at Stanford. (2019). An introduction to design thinking process guide. Retrieved April 22, 2021, from https://dschool-old.stanford.edu/sandbox/groups/designresources/wiki/36873/attac hments/74b3d/ModeGuideBOOTCAMP2010L.pdf.

Kavousi, S., Miller, P. A., \& Alexander, P. A. (2020). Modelling metacognition in design thinking and design making. International Journal of Technology and Design Education, 30(4), 709-735. https://doi.org/10.1007/s10798-019-09521-9

Kelly, T. R., \& Knowles, J. G. (2016). A conceptual framework of integrated STEM education. International Journal of STEM Education. https://doi.org/10.1186/s40594-016-0046-Z

Kolodner, J. L., Camp, P. J., Crismond, C. D., Fasse, B., Gray, J., Holbrook, J., Puntambekar, S., \& Ryan, M. (2003). Problem-based learning meets case-based reasoning in the middle-school science classroom: Putting learning by design ${ }^{\mathrm{TM}}$ into practice. The Journal of the Learning Sciences, 12(4), 495-547. https://doi.org/10.1207/S15327809JLS1204_2

Korur, F., Efe, G., Erdogan, F., \& Tunc, B. (2017). Effects of toy crane design-based learning on simple machines. International Journal of Science and Mathematics Education, 15(2), 251-271. https:// doi.org/10.1007/s10763-015-9688-4

Lamancusa, J., Torres, M., Kumar, V., \& Jorgensen, J. (1996). Learning engineering by product dissection. In The 1996 ASEE Annual Conference. Retrieved April 3, 2021, from https://peer.asee.org/ learning-engineering-by-product-dissection.pdf.

Lammi, M., \& Becker, K. (2013). Engineering design thinking. Journal of Technology Education, 24(2), 55-77. https://doi.org/10.21061/jte.v24i2.a.5

Li, Y., Schoenfeld, A. H., diSessa, A. A., Graesser, A. C., Benson, L. C., English, L. D., \& Duschl, R. A. (2019). Design and design thinking in STEM education. Journal of STEM Education Research, 2(2), 93-104. https://doi.org/10.1007/s41979-019-00020-Z

Li, Y., Wang, K., Xiao, Y., \& Froyd, E. (2020). Research and trends in STEM education: A systematic review of journal publications. International Journal of STEM Education. https://doi.org/10.1186/ s40594-020-00207-6 
Long, C. (2012). Teach your students to fail better with design thinking. Learning and Leading with Technology, 39(5), 16-20.

McGowan, V. C., Ventura, M., \& Bell, P. (2017). Reverse engineering: How students' everyday experiences can support science learning through engineering design. Science and Children, 54(8), 68-72.

McLellan, R., \& Nicholl, B. (2011). If I was going to design a chair, the last thing I would look at is a chair: Product analysis and the causes of fixation in students' design work 11-16 years. International Journal of Technology and Design Education, 21(1), 71-92. https://doi.org/10.1007/s10798-009-9107-7

Mehalik, M. M., Doppelt, Y., \& Schuun, C. D. (2008). Middle-school science through design-based learning versus scripted inquiry: Better overall science concept learning and equity gap reduction. Journal of Engineering Education, 97(1), 71-85. https://doi.org/10.1002/j.2168-9830.2008.tb00955.x

Morgan, G. A., Leech, N. L., Gloeckner, G. W., \& Barrett, K. C. (2013). IBM SPSS for introductory statistics: Use and interpretation. Routledge.

NGSS Lead States. (2013). Next generation science standards: for states, by states. National Academy of Sciences.

Norman, D. (2013). The design of everyday things (Revised and Expanded). Basic Books.

Otto, K. N., \& Wood, K. L. (1998). Product evolution: A reverse engineering and redesign methodology. Research in Engineering Design, 10(4), 226-243. https://doi.org/10.1007/s001639870003

Paparo, M., Dosi, C., \& Vignoli, M. (2017). Towards a DT mindset tool evaluation: Factors identification from theory and practice. In Proceedings of the 21st International Conference on Engineering Design. (pp. 367-376). Vancouver: Canada.

Pleasants, J., \& Olson, J. K. (2019). What is engineering? Elaborating the nature of engineering for K-12 education. Science Education, 103(1), 145-166. https://doi.org/10.1002/sce.21483

Promboon, S., Finley, F. N., \& Kaweekijmanee, K. (2018). The evolution and current status of STEM education in Thailand: Policy directions and recommendations. In G. W. Fry (Ed.), Education in Thailand: An old elephant in search of a new mahout (pp. 423-459). Springer. https://doi.org/10.1007/978-98110-7857-6_17

Quinn, C. M., Reid, J. W., \& Gardner, G. E. (2020). S + T + M = E as a convergent model for the nature of STEM. Science and Education, 29(4), 881-898. https://doi.org/10.1007/s11191-020-00130-w

Razzouk, R., \& Shute, V. (2012). What is design thinking and why is it important? Review of Educational Research, 82(3), 330-348. https://doi.org/10.3102/0034654312457429

Rouse, A. G., \& Rouse, R. (2019). Third graders' use of writing to facilitate learning of engineering concepts. Journal of Research in Science Teaching, 56(10), 1406-1430. https://doi.org/10.1002/tea.21581

Schut, A., Klapwijk, R., Gielen, M., van Doorn, F., \& de Vries, M. (2020). Uncovering early indicators of fixation during the concept development state of children's design processes. International Journal of Technology and Design Education, 30(5), 951-972. https://doi.org/10.1007/s 10798-019-09528-2

Schweitzer, J., Groeger, L., \& Sobel, L. (2016). The design thinking mindset: An assessment of what we know and what we see in practice. Journal of Design, Business and Society, 2(2), 71-94. https://doi. org/10.1386/dbs.2.1.71_1

Sheppard, S. D. (1992). Mechanical dissection: An experience in how things work. In Proceedings of the Engineering Education: Curriculum Innovation \& Integration. Retrieved April 3, 2021, from http:// www-cdr.stanford.edu/images/Dissection/dissphil.pdf.

Subramaniam, K. (1999). Practical physics: Students design appliances containing bimetallic strips. The Science Teacher, 66(4), 37-39.

Sung, E., \& Kelly, T. R. (2019). Identifying design process patterns: A sequential analysis study of design thinking. International Journal of Technology and Design Education, 29(2), 283-302. https://doi.org/ 10.1007/s10798-018-9448-1

The Design-Based Research Collective. (2003). Design-based research: An emerging paradigm for educational inquiry. Educational Researcher, 32(1), 5-8. https://doi.org/10.3102/0013189X032001005

Wahono, B., Lin, P.-L., \& Chang, C.-Y. (2020). Evidence of STEM enactment effectiveness in Asian student learning outcomes. International Journal of STEM Education. https://doi.org/10.1186/ s40594-020-00236-1

Wangka, K., \& Ladachart, L. (2021). Exploring Thai seventh grade students' understanding of design thinking. Journal of Physics: Conference Series, 1835, 012011. https://doi.org/10.1088/1742-6596/1835/1/ 012011

Wendell, K. B., \& Lee, H. (2010). Elementary students' learning of materials science practices through instruction based on engineering design tasks. Journal of Science Education and Technology, 19(6), 580-601. https://doi.org/10.1007/s10956-010-9225-8

Wendell, K. B., \& Rogers, C. (2013). Engineering design-based science, science content performance, and science attitudes in elementary school. Journal of Engineering Education, 102(4), 513-540. https:// doi.org/10.1002/jee.20026 
Wood, K. L., Jensen, D., Bezdek, J., \& Otto, K. N. (2001). Reverse engineering and redesign: Courses to incrementally and systematically teach design. Journal of Engineering Education, 90(3), 363-374. https://doi.org/10.1002/j.2168-9830.2001.tb00615.x

Wrigley, C., \& Straker, K. (2015). Design thinking pedagogy: The education design ladder. Innovations in Education and Teaching International, 54(4), 374-385. https://doi.org/10.1080/14703297.2015.11082 14

Younis, M. B., \& Tutunji, T. (2012). Reverse engineering course at Philadelphia University. European Journal of Engineering Education, 37(1), 83-95. https://doi.org/10.1080/03043797.2012.658508

$\mathrm{Yu}, \mathrm{C}-\mathrm{H}$. (2021). Threats to validity of research design. Retrieved April 4, 2021, from http://www.creativewisdom.com/teaching/WBI/threat.shtml.

Zhong, B., Kang, S., \& Zhan, Z. (2020). Investigating the effect of reverse engineering pedagogy in K-12 robotics education. Computer Applications in Engineering Education. https://doi.org/10.1002/cae. 22363

Publisher's Note Springer Nature remains neutral with regard to jurisdictional claims in published maps and institutional affiliations. 